$$
\text { The rich legacy of Erwin Schrödinger }
$$

\author{
P. W. Atkins
}

Schrödinger: Centenary Celebration of a Polymath. Edited by C. W. Kilmister. Cambridge University Press:1987. Pp.253. £30, \$54.50.

ERWIN Schrödinger was born a hundred years ago, on 12 August 1887. This volume contains the lectures delivered at the conference that was held in London at the end of March to celebrate his contributions to science.

Schrödinger's fame rests on his discovery of the equation that bears his name; this is a second-order partial differential equation, which depends on the masses of the particles and the potential they experience, and which underlies so many of the applications of quantum mechanics. Yet Schrödinger was active in fields much wider than the equation itself and his work spans almost the entire compass of fundamental science. We can trace the origins of gauge theory in his thoughts, and he made stimulating comments on the application of physics to biology.

Although his early life was spent in Austria, his first major appointment was in Zurich where he remained until he succeeded Planck in Berlin in 1927, shortly after the publication of his equation. In 1933, the year he shared the Nobel Prize with Dirac, Hitler's rise to power drove him, perhaps unnecessarily, from the country. He spent three unhappy, homesick years in Oxford before he returned to Graz in 1936. That too was unwise, for he arrived just in time to flee before the Anschluss,

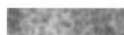

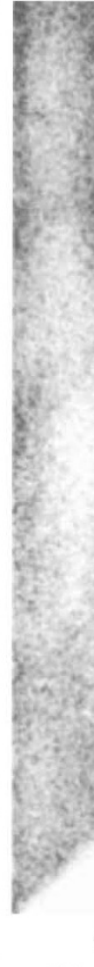

first to Rome and then, in 1940, to Eire, into the welcoming arms of de Valera. There he joined the newly created Dublin Institute for Advanced Studies, de Valera's brain child, and for 15 years was the director of its School of Theoretical Physics. In the end he returned to Austria and died in Alpach in 1961.

Schrödinger was 39 when he discovered his equation, an old fogey in comparison with most of his contemporaries (Heisenberg was 24, Dirac 24, Jordan 23, Pauli 25 and Einstein 26 when they were contributing to the subject most fruitfully) and almost too old for the task of adjusting to the transition from the old physics. Indeed, he clung to classical modes of thought, and originally proposed his equation as a classical theory of matter waves directly analogous to Maxwell's theory of electromagnetic waves. Questions of interpretation have been as much a part of Schrödinger's legacy as has been the practical use of his formulation of quantum mechanics, and two of the contributions deal with aspects of this problem. Dorling explores what we would need to accept if Schrödinger's own interpretation of his equation were to be valid and examines the consequences of regarding it as a non-local theory. He sees the possibility that Schrödinger's interpretation may not only have been too hasty but that the potential of the Schrödinger

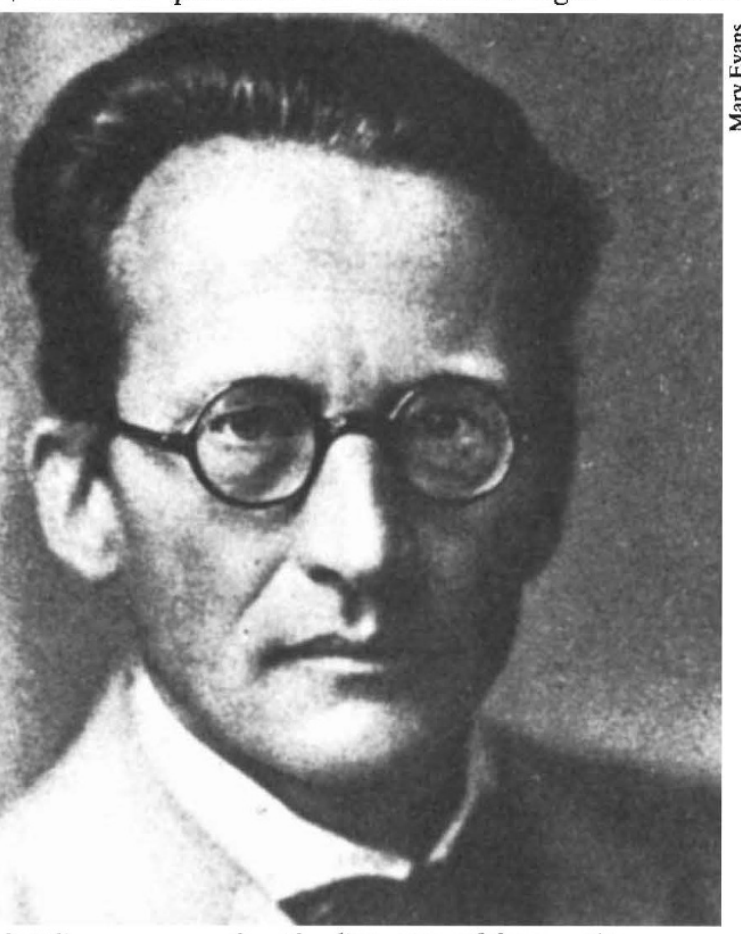

chrödinger - more than the discoverer of the equation.

equation for calculating physical properties may have been underestimated.

Schrödinger was also shocked by quantum jumps, and hoped that his equation would evade them by replacing them with the smooth unfurling of the wavefunction. He was distressed by the realization that they remained intrinsic to his formulation ("If we have to go on with these damned quantum jumps, then I'm sorry that I ever got involved"). He would probably have been even more upset by Bell's tentative espousal of Ghirardi, Rimini and Weber's suggestion that, yes indeed, the wavefunction evolves smoothly according to the Schrödinger equation, but from time to time makes a jump, one that perhaps kills the cat. These cobbled theories are never very pretty when first proposed but, as Bell remarks, they may be a hint of better things to come. After all, since the Aspect experiment we are having to adjust ourselves to a more abstract, non-local sense of the world.

Schrödinger's longest-lasting contribution to the mathematical description of the world may be less his equation itself than its implication that complex numbers are an intrinsic feature of our description of nature. Yang explores this point, which arises from Dirac's remark that "the real genius of Heisenberg and Schrödinger ... was to discover the existence of phase amplitudes". Yang points out that the importance of this discovery was not fully appreciated until the $1970 \mathrm{~s}$, with the development of gauge theories and the recognition of their relation to fibre bundles. There is now a general acceptance of the view that all fundamental forces are phase fields. Schrödinger's "almost casual" introduction of $i$ into physics other than as a calculational device is the principal acorn planted by his work.

With the groundwork of interpretation examined, the contributions turn to a consideration of the features that can be calculated from the Schrödinger equation. Here I particularly enjoyed Thirring's survey of theorems relating to putative exact solutions of the manyelectron equation for atoms and molecules, where we see how, contrary to their initial expectation, analysts seem to have progressed further with the many-body Schrödinger equation than with the corresponding classical problem. That is just as well, since the Schrödinger equation is the chemist's equivalent of the philosopher's stone: without the concepts it inspires and its calculational power chemistry would be hamstrung. A little of the efflorescence of this power is evident in Karplus's account of the chemist's first, tentative calculation of the potential energy surface of the $\mathrm{H}+\mathrm{H}_{2}$ reaction trajectory burgeoning into their capacity to compute the dynamics of enzyme molecules containing thousands of atoms and surrounded by water molecules. In Buckingham's article we see how the ability of chemists to compute precise values using the Schrödinger equation has sometimes outstripped the experimentalist's precision, and has guided them to better interpretations of their data. Without the Schrödinger equation we would be unable to speak in terms of orbitals, and would be unable to face up to the sort of description of reactions that Fukui describes and which depend essentially on the language the equation provides.

However, these massive problems appear almost microcosmic when Hawking expands the concept to the Universe, and explores the possibility that when the 
Schrödinger equation is applied on this scale it eliminates the initial singularity in much the same way as its application to more conventional, smaller systems comes into its own at a point where classical physics breaks down. With this, the ultimate extension of the application of his equation to the Universe, Schrödinger would have been enthralled.

There is no space for me to examine all the papers in this volume, which includes contributions on boson condensation (Lewis), nonlinear optics (McConnell), unified field theories and particles (Hittmair, Salam), astronomy and astrophysics (Kibble, Seaton) and biology (Pauling, Perutz). In a sense that is best, for I must confess that I could not help being sympathetic to Pauling's somewhat egocentric contribution and in particular his view that Schrödinger's later work on biology, as recounted in What is Life?, was confused and misleading.

So much for Schrödinger the equation, what of Schrödinger the man? He remains elusive in these pages. Flamm explores his grandfather Boltzmann's considerable influence on Schrödinger. Despite the fact that they never met, Boltzmann was the spring of Schrödinger's interest in science: "His line of thought may be called my first love in science. No other has ever thus enraptured me or will ever do so again". Here are the roots of Schrödinger's attitudes and Boltzmann's work was often the point of departure for Schrödinger's own, including that on quantum mechanics. Their mutual admiration of Darwin was also the stimulus and support for Schrödinger's foray into biology, in which he sought, but more tentatively than Boltzmann, the physical basis of life. A cleare vision of the personality of de Valera, a thwarted academic who rechannelled his energies into politics, comes from McCrea's fascinating account of the emergence of the Dublin Institute and Schrödinger's involvement with it.

The scientific world directly and the general world indirectly has much to be grateful for in the life of Erwin Schrödinger. His was not so great a discovery that it would not have been made, perhaps within months, by others. Yet it fell to him to be first, and he had the power and confidence to explore many of its implications. That he left a rich legacy of calculational power and troublesome problems of the kind surveyed here is an epitaph he would have relished. These papers show that he reaches (as his later writings suggest he would like to think) from beyond the grave to tickle the intellect with the conundrums of quantum mechanics and to view the flourishing tree into which his acorn has grown.

P. W. Atkins is University Lecturer in Physical Chemistry at the University of Oxford, and a Fellow of Lincoln College, Oxford OX1 3DR, UK.

\section{Feasting with the Olympians}

\section{Walter Gratzer}

The Life It Brings: One Physicist's Beginnings. By Jeremy Bernstein. Ticknor \& Fields, New York: 1987. Pp. 171. \$16.95.

JEREMY Bernstein is a theoretical physicist, turned writer. He must, one surmises, have been a pretty good physicist for he broke bread with the likes of Yang, Lee and Gell-Mann; that he is a very good writer indeed is plain. His all-too-brief memoir began (like so much of the best science writing of recent years) as articles in the New Yorker and it is a wholly captivating read.

Bernstein conjures up for us his journey from a cultured middle-class Jewish home through one of the great New York high schools, cradle of Nobel Laureates (as for instance the St Elizabeth Gymnasium in Budapest once was in the intellectual heyday of Central Europe) and thence in 1947 to Harvard. There he slowly discovered his vocation by a process of trial and error that would be impossible in a British university and moved by way of pure mathematics into theoretical physics. He came under the influence first of Philipp Frank, student of Boltzmann and friend of Einstein, who embodied the European cultural tradition, and then of the remarkable indigenous school of younger physicists, led by the incomparable Julian Schwinger. It was Bernstein's first brush with genius. Schwinger was adulated and imitated by his students: to say "nucular", it seems, marked you as one of his followers. His lectures (like those of Feynman on the Western seaboard) were the stuff of academic legend (which certainly percolated into other Harvard Departments, such as Chemistry, as I well recall): they were delivered without notes, and the subject was developed anew at the blackboard, impromptu, mathematics and all.

Schwinger was a prodigy, who had taught himself physics and mathematics from the Encyclopaedia Britannica. Bernstein relates the story of the adolescent's encounter with I. I. Rabi at Columbia. Rabi had summoned his then student, the astronomer Lloyd Motz, to his office to discuss a paper. Motz asked if he might bring in someone who was waiting for him outside. "He brought in this kid in knee pants", Rabi recalled. "So I told him to sit down some place, and he sat down. Motz and I were arguing, and this kid pipes up and settles the argument. And I said, "Who the hell is this'?". Rabi eventually prised the lad away from City College, where he was failing courses in everything but physics, and with difficulty got him into Columbia.
Bernstein's later contact with the sinister world of the atom bomb and the dark contagion that seeped into physics from Los Alamos - - the physicists, in Oppenheimer's words, had known evil - was prefigured by his acquaintance with Wendell Furry. Furry had been a communist, but heroically refused to "take the Fifth" when arraigned before the House UnAmerican Activities Committee, and was broken, like Oppenheimer, on McCarthy's wheel. His was, Bernstein thought, a maimed personality. There is a poignant vignette of Furry, who had in happier times been regarded as an outstanding theoretician, sitting in on Schwinger's lectures, turning over the pages of Time magazine.

From Harvard Bernstein progressed to the Institute of Advanced Studies, presided over by Robert Oppenheimer. It was the high noon of the Institute: T.D. Lee, C.N. Yang and a host of other luminaries were in residence, and Bohr, Dirac and Pauli were frequent visitors. "We will have a ball", Oppenheimer had said to Bernstein before he arrived. Bernstein attached himself to a genial young physicist, Marvin Goldberger (now President of Caltech), and together they tackled some problems concerning the interaction of fundamental particles. One of their col-

"Pauli was noted for intolerance and intellectual thuggery ('So young', he was supposed to have snarled as a student brought his research seminar to a close, 'and already he has accomplished so little')."

leagues was Freeman Dyson, of whose prodigious mathematical powers Bernstein speaks with awe. His first experience came when Dyson wandered into the room as Bernstein and Goldberger were brooding over an integral equation of seemingly unfathomable complexity. Invited to examine it, Dyson owned that he was feeling especially strong that morning and offered to have a go at it. Twenty minutes later he returned with the solution - later rediscovered and published by two other workers, whose name it bears. "I cannot imagine", Bernstein writes, "what it must feel like to think with that rapidity and clarity in mathematics. Does everyone else appear to be going in slow motion? But I have learned enough mathematics to get pleasure and delight each time I see it happening".

When the end of Bernstein's contract approached, Oppenheimer proposed a period in Europe with Wolfgang Pauli, but a lecture given by Pauli at Columbia persuaded Bernstein that the great man's powers were in a state of terminal decline (and indeed he died soon after at the age of 58). Pauli was noted for intolerance and intellectual thuggery ("So young", he was supposed to have snarled as a student 